(2) Open Access Full Text Article

\title{
A first-in-man study to evaluate the safety, tolerability, and pharmacokinetics of pasireotide (SOM230), a multireceptor-targeted somatostatin analog, in healthy volunteers
}

This article was published in the following Dove Press journal:

Drug Design, Development and Therapy

30 March 2012

Number of times this article has been viewed

\author{
Georg Golor' \\ $\mathrm{Ke} \mathrm{Hu}{ }^{2}$ \\ Matthieu Ruffin ${ }^{3}$ \\ Alexandra Buchelt ${ }^{3}$ \\ Emmanuel Bouillaud ${ }^{3}$ \\ Yanfeng Wang ${ }^{2}$ \\ Mario Maldonado 3 \\ IPAREXEL International GmbH, Berlin, \\ Germany; ${ }^{2}$ Novartis Pharmaceuticals, \\ East Hanover, NJ, USA; ${ }^{3}$ Novartis \\ Pharma AG, Basel, Switzerland
}

Correspondence: Georg Golor Early Phase Clinical Unit - Berlin, PAREXEL International $\mathrm{GmbH}$, Klinikum Westend - Haus 18 Spandauer Damm 130, 14050 Berlin, Germany

Tel +4903030685158

Fax +49030 306857017

Email georg.golor@parexel.com

\begin{abstract}
Pasireotide (SOM230) is a multireceptor-targeted somatostatin analog with high binding affinity for four of the five somatostatin receptor subtypes ( $\mathrm{sst}_{1,2,3}$ and $\mathrm{sst}_{5}$ ), and potential clinical activity in several neuroendocrine and oncologic conditions, including acromegaly, Cushing's disease, and neuroendocrine tumors (NET). This manuscript reports the first-in-man dose-escalation study of pasireotide, evaluating its safety, tolerability, and pharmacokinetics (PK) in healthy male volunteers. A single dose of pasireotide $1-1200 \mu \mathrm{g}$ was administered subcutaneously in four to eight subjects per dose level, with two additional subjects per cohort administered placebo. PK and safety evaluations were carried out over 7 days post-dose. Growth hormone (GH) suppression was evaluated using a GH-releasing hormone stimulation test on Day -1 and Day 1 at 3-5 hours post-injection. Seventy-two subjects completed the study. Pasireotide was well tolerated with no serious adverse events observed at any dose. Transient elevations in blood glucose levels were observed 2-6 hours after administration of pasireotide at doses between 200 $\mu \mathrm{g}$ and $1200 \mu \mathrm{g}$, but this resolved without intervention by 23 hours post-dosing. The maximum tolerable dose was not established within the tested range. Pasireotide demonstrated a favorable PK profile with fast absorption ( $\mathrm{t}_{\max }: 0.25-0.5$ hours), low clearance (CL/F: 8-13 L/hour), long effective elimination half-life (mean $\mathrm{t}_{1 / 2, \beta}: 7-11$ hours), and a proportional dose-exposure relationship. GH suppression of $79 \%-96 \%$ was observed at single pasireotide doses between $200 \mu \mathrm{g}$ and $1200 \mu \mathrm{g}$. In conclusion, pasireotide demonstrated favorable safety, tolerability, and PK profiles, as well as promising activity in suppressing the release of GH. The efficacy and safety of pasireotide is currently being evaluated in patients with acromegaly, Cushing's disease, NET, and various non-neuroendocrine disorders.
\end{abstract}

Keywords: pasireotide, safety, tolerability, pharmacokinetics, healthy volunteers

\section{Introduction}

Pasireotide is a multireceptor-targeted somatostatin analog that exerts its pharmacologic activity through binding to somatostatin receptor subtypes (sst). The rationally designed cyclohexapeptide structure of pasireotide incorporates synthetic amino acids to achieve an enhanced sst binding profile compared with currently available somatostatin analogs octreotide and lanreotide (Table 1, Figure 1). Whereas octreotide and lanreotide bind with greatest affinity to $\mathrm{sst}_{2}$, pasireotide has high binding affinity for four of the five sst. ${ }^{1}$ Pasireotide has a 39-, 30- and 5-fold higher binding affinity for $\mathrm{sst}_{5}$, sst $_{1}$, and $\mathrm{sst}_{3}$, respectively, and 2.6 times lower affinity for $\mathrm{sst}_{2}$ compared with octreotide. ${ }^{1}$ Pasireotide also has a 2-fold higher binding affinity for sst ${ }_{5}$ than endogenous somatostatin. ${ }^{2,3}$ More- 
Table I Binding affinities of somatostatin (SRIF- I4), pasireotide, octreotide, and lanreotide to the five human sst'

\begin{tabular}{lccccc}
\hline Compound & sst $_{\text {1 }}$ & sst $_{2}$ & sst $_{3}$ & sst $_{\mathbf{4}}$ & sst $_{\text {5 }}$ \\
\hline Somatostatin (SRIF-14) & $0.93 \pm 0.12$ & $0.15 \pm 0.2$ & $0.56 \pm 0.17$ & $1.50 \pm 0.4$ & $0.29 \pm 0.04$ \\
Pasireotide & $9.3 \pm 0.1$ & $1.0 \pm 0.1$ & $1.5 \pm 0.3$ & $>1000$ & $0.16 \pm 0.01$ \\
Octreotide & $280 \pm 80$ & $0.38 \pm 0.08$ & $7.1 \pm 1.4$ & $>1000$ & $6.3 \pm 1.0$ \\
Lanreotide & $180 \pm 20$ & $0.54 \pm 0.08$ & $14 \pm 9$ & $230 \pm 40$ & $17 \pm 5$ \\
\hline
\end{tabular}

Notes: Results are the mean \pm SEM of $I_{50}$ values expressed as nmol/L. C) European Society of Endocrinology 2002, reproduced with permission.'

over, pasireotide exhibits greater metabolic stability than octreotide because of the presence of a Cys-Cys bridge that protects the stability of the amide bond in the cyclic ring, ${ }^{1,4}$ which may translate into a prolonged pharmacologic effect compared with octreotide.

Because of this unique binding profile and a more metabolically stable chemical structure than octreotide, pasireotide may offer new opportunities for therapeutic application. ${ }^{1,5}$ Pasireotide is being evaluated in patients with acromegaly ${ }^{6-9}$ and neuroendocrine tumors (NET), ${ }^{10,11}$ including patients who are resistant or refractory to octreotide LAR, as well as in medically naïve and/or de novo patients. Pasireotide also has potential to be a tumor-targeted management option for patients with Cushing's disease, a patient population in whom currently available somatostatin analogs are ineffective. Pasireotide has demonstrated efficacy in patients with Cushing's disease in a large, randomized, Phase III trial. ${ }^{12}$
This manuscript reports the results of the first-in-man study investigating the safety, tolerability, pharmacokinetics (PK), and pharmacodynamics (PD) of a single subcutaneous injection of pasireotide administered to healthy volunteers.

\section{Methods}

\section{Subjects}

Study subjects were male volunteers aged 18-40 years, in good health as determined by a suitable medical history and normal findings from evaluations performed at screening (eg, physical examination, vital signs, electrocardiograph, and laboratory tests). Subjects were enrolled only if their liver function tests, including serum glutamic oxaloacetic transaminase (SGOT, ie, aspartate transaminase) and serum glutamic pyruvic transaminase (SGPT, ie, alanine transaminase), were within the normal range; gamma-glutamyl transpeptidase (GGT) and alkaline phosphatase (ALP) did
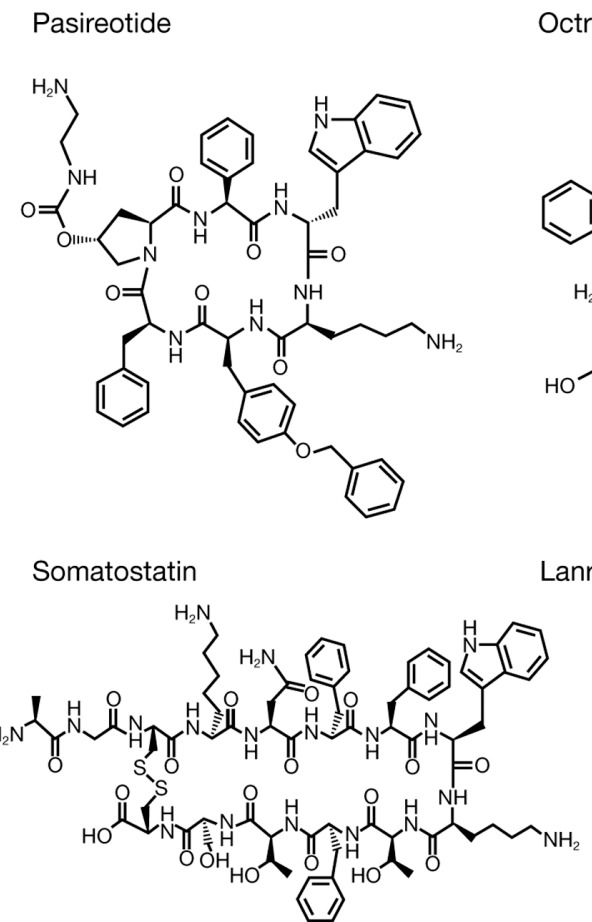

Octreotide

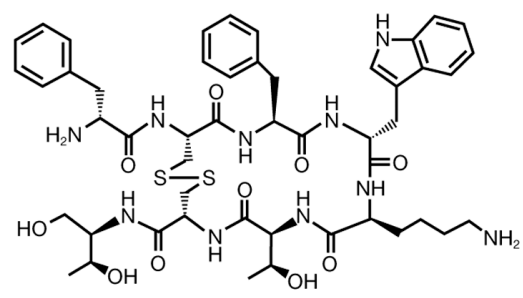

anreotide

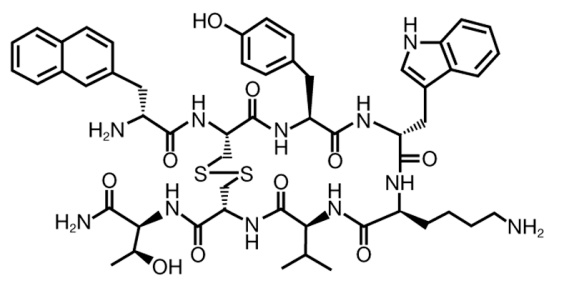

Figure I Chemical structures of pasireotide, somatostatin (SRIF-I4) and other somatostatin analogs.

Notes: The molecular weights of pasireotide free base, somatostatin, octreotide and lanreotide are 1047 kDa, 1638 kDa, 1019 kDa, and 1096 kDa, respectively. The molecular weight of the pasireotide diaspartate salt form is $1313 \mathrm{kDa}$. 
not exceed twice the upper limit of the normal (ULN) range and serum bilirubin did not exceed $27 \mu \mathrm{mol} / \mathrm{L}(1.6 \mathrm{mg} / \mathrm{dL})$. Subjects underwent a right-upper-quadrant abdominal ultrasound to rule out any cholelithiasis (symptomatic or asymptomatic gallstone disease).

Subjects were excluded from the trial if they had previous/ current gall bladder disease, pancreatic injury/pancreatitis, liver disease/injury, impaired renal function, autonomic dysfunction, acute or chronic bronchospastic disease, a clinically significant drug/atopic allergy or had undergone major gastrointestinal tract surgery. Subjects were also excluded if they had taken any prescription or over-the-counter drugs (excluding paracetamol) within 2 weeks prior to dosing or donated $\geq 400 \mathrm{~mL}$ of blood within 8 weeks prior to pasireotide administration. Before enrolment into the trial, subjects were to abstain from strenuous physical exercise, alcohol, and caffeine starting 7 days, 72 hours, and 48 hours before pasireotide administration, respectively.

\section{Study design}

This was a single-center, randomized, double-blind, placebocontrolled, time-lagged, parallel-group, ascending, singledose study of pasireotide subcutaneously administered to healthy volunteers. Pasireotide was administered between 8 am and 9 am, approximately 1 hour after eating a light standardized meal. As such, the effect of pasireotide on blood glucose was investigated in a post-prandial state.

The study design called for eight subjects each to be randomized into seven cohorts of pasireotide 1, 2.5, 10, 30, 100,300 or $600 \mu \mathrm{g}$ administered subcutaneously. Of these eight subjects, six in each cohort were to receive pasireotide and two were to receive placebo. A dispensing error resulted in four subjects being administered $200 \mu \mathrm{g}$ pasireotide instead of $100 \mu \mathrm{g}$ pasireotide. A protocol amendment allowed administration of $100 \mu \mathrm{g}$ pasireotide to be restudied in new subjects, and an additional cohort administered $1200 \mu \mathrm{g}$ pasireotide was included.

Pasireotide doses were administered to cohorts in ascending order. Before escalation to the next cohort, at least six subjects from the previous cohort had to demonstrate adequate safety/tolerability for up to 48 hours post-dose. Subjects were confined to the study center from approximately 36 hours before administration until the availability of 48 -hour postdose safety results.

The study was randomized by a validated system. All subjects provided informed consent, and the study was conducted in accordance with the Declaration of Helsinki (World Medical Association Inc, Ferney-Voltaire, France).

\section{Study medication}

Doses of 1, 2.5, 10, 30, 100, 300, 600, and $1200 \mu \mathrm{g}$ of pasireotide were administered subcutaneously. Pasireotide was provided as either $0.15 \mathrm{mg}$ or $3 \mathrm{mg}$ per $3 \mathrm{~mL}$ vials. For the $1 \mu \mathrm{g}$ and $2.5 \mu \mathrm{g}$ doses, pasireotide solutions were prepared by diluting a $0.15 \mathrm{mg}$ per $3 \mathrm{~mL}$ solution 5 -fold in the matching placebo solution to a final concentration of $0.03 \mathrm{mg}$ per $3 \mathrm{~mL}$; doses of $1 \mu \mathrm{g}$ and $2.5 \mu \mathrm{g}$ were then administered as $0.1 \mathrm{~mL}$ and $0.25 \mathrm{~mL}$ of the 5 -fold diluted solution. Doses of $10 \mu \mathrm{g}$ and $30 \mu \mathrm{g}$ were administered as $0.2 \mathrm{~mL}$ and $0.6 \mathrm{~mL}$ of the $0.15 \mathrm{mg}$ per $3 \mathrm{~mL}$ solution, respectively, while doses of $100,200,300,600$, and $1200 \mu \mathrm{g}$ were administered as 0.1 , $0.2,0.3,0.6$, and $1.2 \mathrm{~mL}$ of the $3 \mathrm{mg}$ per $3 \mathrm{~mL}$ solution, respectively.

\section{Safety, PK, and PD assessments}

The primary objective of the study was to evaluate the safety and tolerability of a single subcutaneous dose of pasireotide in healthy subjects. Safety was assessed continuously throughout the study by physical examination, vital signs, blood pressure, laboratory parameters, and electrocardiogram (ECG) recordings at screening, baseline, regular intervals throughout the study day, and at the end-of-study visit (Day 7). Hematology, blood chemistry and urinalysis evaluations were also performed regularly. Adverse events (AEs) were recorded throughout the study, as reported by patients, identified by investigator questioning, or detected through physical examination, laboratory test or other means. Abnormal laboratory values were considered as AEs only if they produced clinical signs or symptoms, or required therapy. Serious AEs (SAEs) were recorded up to 4 weeks after the conclusion of the trial.

The secondary objectives were to assess the PK and PD profiles associated with a single dose of pasireotide, and to identify the pharmacologically active range of pasireotide doses. Blood samples for PK assessment were taken at designated time points up to 144 hours post-dose by either direct venipuncture or an indwelling cannula inserted into a forearm vein. Plasma samples were obtained after centrifugation of blood samples. Plasma concentrations of pasireotide were determined by a validated radioimmunoassay with the lower limit of quantification (LLOQ) of $0.03 \mathrm{ng} / \mathrm{mL}(30 \mathrm{pg} / \mathrm{mL})$. PK parameters were derived by non-compartmental analysis using WinNonlin software (v 5.2; Pharsight Corporation, Mountain View, CA) and included maximum observed plasma concentration after drug administration $\left(\mathrm{C}_{\max }\right)$, time to reach $\mathrm{C}_{\max }\left(\mathrm{t}_{\max }\right)$, halflife $\left(t_{1 / 2, \alpha}, t_{1 / 2, \beta}, t_{1 / 2, \gamma}\right)$, area under the plasma concentration-time 
curve calculated to the last quantifiable concentration point $\left(\mathrm{AUC}_{\text {last }}\right)$, area under the plasma concentration-time curve extrapolated to infinity $\left(\mathrm{AUC}_{\infty}\right)$, apparent volume of distribution $\left(\mathrm{V}_{\mathrm{z}} / \mathrm{F}\right)$, and apparent total body clearance $(\mathrm{CL} / \mathrm{F})$. All blood samples taken for laboratory samples were assessed centrally by $\mathrm{W} \& \mathrm{~T} \mathrm{GmbH}$ (Berlin, Germany).

A growth hormone-releasing hormone (GHRH) stimulation test was performed on Day -1 and 3-5 hours after pasireotide administration on Day 1 for PD assessment. Subjects were administered a GHRH bolus of $1 \mu \mathrm{g} / \mathrm{kg}$ at approximately 3 hours after pasireotide administration. Plasma GH levels were obtained at -60 minutes and 0 minutes (just before injection of GHRH), and at designated time points up to 120 minutes after GHRH administration (ie, up to approximately 5 hours after pasireotide administration). Plasma GH levels were determined by a chemiluminescence assay with a LLOQ of $0.06 \mathrm{ng} / \mathrm{mL}$.

Blood glucose measurement was part of the standard laboratory assay. Blood glucose levels were measured immediately before and 60 minutes after a standard lunch on Day -1 and Day 1 , as well as 2 hours after pasireotide administration on Day 1, to evaluate possible drug effects on glycemia. Glucose levels were also measured on Day 2 at 23 hours after pasireotide administration.

\section{Statistical analyses}

Descriptive statistics were provided for vital signs, ECG evaluations, standard clinical laboratory evaluations, and AEs. The assessment of safety/tolerability was based on the frequency of AEs and on the number of laboratory values that fell outside pre-determined ranges.

All concentrations below the LLOQ were treated as zero in the concentration data listings. Summary descriptive statistics were provided for PK parameters. In order to determine the dose-proportional relationship for the PK exposures $\left(\mathrm{C}_{\max }, \mathrm{AUC}_{\text {last }}\right.$ and $\left.\mathrm{AUC}_{\infty}\right)$, linear models were fitted on the log-transformed $\mathrm{PK}$ parameters with log-transformed dose as the independent variable (Equation 1):

$\ln (\mathrm{PK}$ parameter $)=\ln (\mathrm{a})+\mathrm{b} * \ln ($ dose $)+$ error

The slope $\mathrm{b}$ and the relative $90 \%$ confidence interval (CI) for $b$ were estimated. Given the dose-range ratio considered (highest dose/lowest dose $=\mathrm{Rd}$ ), the critical region, within which the $90 \%$ CI for the slope needs to be contained in order to conclude dose proportionality, can be derived as $1+\ln (0.8) / \ln (\mathrm{Rd}), 1+\ln (1.25) / \ln (\mathrm{Rd})$, where $(0.80,1.25)$ is the standard acceptance interval for $\mathrm{Rd}$.

Lack of fit of the model was tested for deviation from linearity on the log scale at the 5\% significance level. This was done by adding a factor (dose) in the log-transformed linear regression model. The type I test for dose is the test for lack of fit. The final dose range kept in the model was the one for which the lack of fit test did not meet the $5 \%$ significance level.

The relationship between the dose of pasireotide and the effect on GHRH-stimulated GH secretion was investigated using appropriate graphical and exploratory statistical methods. Analysis of the data was performed using SAS ${ }^{\circledR}$ (v 8.2; SAS Institute Inc, Cary, NC). The GH ratio was calculated as the 2-hour GH AUC ( $\mathrm{AUC}_{2 \mathrm{~h}}$; taken between 3-5 hours post-dose) in each dose group divided by the 2-hour AUC on the control day (Day -1). A non-linear $\mathrm{E}_{\text {max }}$ sigmoid model (Equation 2) was used to describe the relationship between the pasireotide dose and the GH AUC ratio, where $\mathrm{E}_{\max }$ is the maximum $\mathrm{GH}$ reduction and $\mathrm{ED}_{50}$ is the pasireotide dose to yield half of the maximum $\mathrm{GH}$ reduction:

$$
\mathrm{GH}-\text { ratio }=\frac{\mathrm{AUC}_{2 \mathrm{~h}, \text { treat }}}{\mathrm{AUC}_{2 \mathrm{~h}, \text { cont }}}=1-\frac{\mathrm{E}_{\max }}{\mathrm{ED}_{50}+\text { dose }}
$$

A similar analysis was performed using the equation above (Equation 2) with the average pasireotide plasma concentration over the 2-hour window during the GHRH challenge test $\left(\mathrm{C}_{\mathrm{avg}}\right)$ as the independent parameter in place of dose, and $\mathrm{EC}_{50}$ (defined as the pasireotide concentration to yield half of the maximum $\mathrm{GH}$ reduction) in place of $\mathrm{ED}_{50}$.

\section{Results}

\section{Subject demographics}

Seventy-two healthy male subjects were enrolled. All subjects completed the study except for one in the lowest pasireotide dose cohort $(1 \mu \mathrm{g})$ who did not return for the end-of-study visit. The demographic details of the volunteers are summarized in Table 2. All 72 subjects were included in all analyses.

\section{Safety/Tolerability}

Pasireotide was generally well tolerated and there were no reports of death, SAEs, or clinically significant changes in laboratory values, vital signs or ECG parameters. Nine subjects experienced a total of 12 AEs, eight of which were considered related to the study drug. Drug-related AEs were observed in the $1200 \mu \mathrm{g}$ dose group only. Five AEs were of moderate severity and seven AEs were considered mild.

Among subjects administered pasireotide at doses lower than $1200 \mu \mathrm{g}$, two experienced an AE (one subject experienced two episodes of abdominal discomfort with pasireotide 


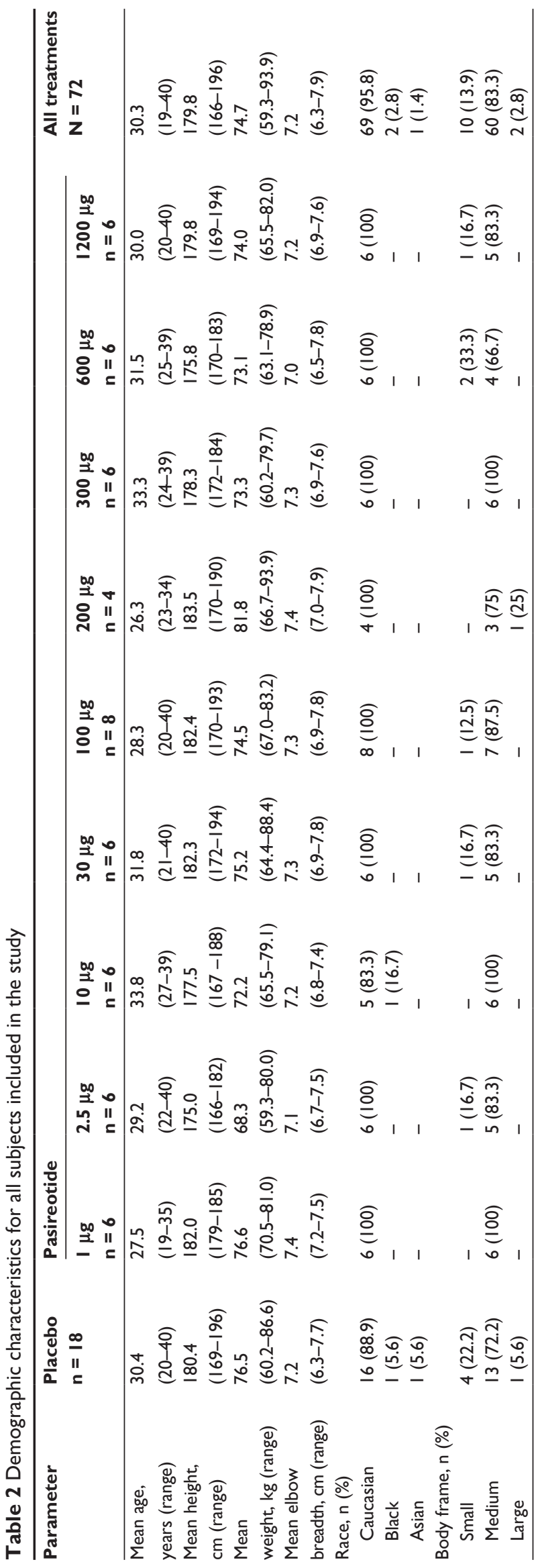

$100 \mu \mathrm{g}$, both of mild intensity, and one subject experienced an episode of influenza of moderate intensity with pasireotide $600 \mu \mathrm{g})$. These events were not considered to be related to the study medication. At the pasireotide $1200 \mu \mathrm{g}$ dose, all subjects $(n=6)$ experienced at least one AE, five of whom experienced nausea. The AEs generally started about 1 hour after the pasireotide injection and lasted for approximately $2-3$ hours. None of these subjects received medications for treatment of an AE. One subject receiving placebo had an AE of oral herpes of moderate intensity.

AEs considered treatment related included five events of nausea (three mild and two moderate), and one event each of headache of mild intensity, dizziness of mild intensity, and vomiting of moderate intensity. AEs considered unrelated to pasireotide treatment were herpes labialis, influenza, and two episodes of abdominal discomfort.

Two subjects administered pasireotide $2.5 \mu \mathrm{g}$ and $10 \mu \mathrm{g}$ displayed increased lipase levels of $547 \mathrm{U} / \mathrm{L}$ and $523 \mathrm{U} / \mathrm{L}$, respectively, 48 hours post-dose (normal range: 23-300 U/L), which was considered possibly related to the study drug. Lipase levels had returned to the normal range when lipase levels were next measured, at the end-of-study visit (Day 7). One placebo recipient had lipase values four times greater than the ULN (1247 U/L) 24 hours after receiving placebo. In this subject, lipase levels returned to within the normal range at 48 hours after placebo administration. No clinical findings were associated with increased lipase levels in these subjects. Amylase levels were normal in these subjects.

\section{Blood glucose levels}

One hour before pasireotide administration (pre-breakfast), the mean glucose levels were similar between groups $(87.7 \mathrm{mg} / \mathrm{dL}$ in the placebo group and $81.1-97.9 \mathrm{mg} / \mathrm{dL}$ with pasireotide 1-1200 $\mu \mathrm{g}$ ). Two hours after study drug administration, the mean glucose level in the placebo group was $82.6 \mathrm{mg} / \mathrm{dL}$. Glucose levels in subjects administered pasireotide 1-100 $\mu \mathrm{g}$ were similar to those of placebo recipients, whereas mean glucose levels in subjects administered pasireotide $\geq 200 \mu \mathrm{g}$ were higher than those of placebo recipients. In the pasireotide $200,300,600$, and $1200 \mu \mathrm{g}$ dose groups, mean glucose levels were 126.6, 116.2, 172.7, and $145.5 \mathrm{mg} /$ $\mathrm{dL}$, respectively, 2 hours after pasireotide administration.

Six hours after the administration of pasireotide, only subjects administered the two highest doses of pasireotide (600 $\mu \mathrm{g}$ and $1200 \mu \mathrm{g}$ ) had glucose levels higher than those of placebo recipients. Twenty-three hours after the injection, glucose values were normal for all groups. 


\section{Pharmacokinetics}

At a dose of $1 \mu \mathrm{g}$, pasireotide concentrations were below the LLOQ $(0.03 \mathrm{ng} / \mathrm{mL})$ and this dose was therefore excluded from the calculation of PK parameters. As shown in Figure 2 following a single dose of pasireotide 2.5-1200 $\mu \mathrm{g}$, the mean plasma concentration versus time profiles of pasireotide appeared to demonstrate mono-exponential disposition for doses 2.5-10 $\mu \mathrm{g}$ (with an $\alpha$ phase), bi-exponential disposition for doses 30-300 $\mu \mathrm{g}$ (with $\alpha$ and $\beta$ phases), and triexponential disposition for doses 600-1200 $\mu$ g (with $\alpha, \beta$, and $\gamma$ phases), which appeared to depend on the pasireotide plasma concentration levels in reference to the LLOQ of $0.03 \mathrm{ng} / \mathrm{mL}$.

As shown in Table 3, the $t_{1 / 2}$ values of pasireotide in the $\alpha$ phase $\left(\mathrm{t}_{1 / 2, \alpha}: 1-2\right.$ hours $)$ and $\beta$ phase $\left(\mathrm{t}_{1 / 2, \beta}: 7-11\right.$ hours $)$ were similar across dose levels. The mean values of $t_{1 / 2}$ in the $\gamma$ phase $\left(t_{1 / 2, \gamma}\right)$ were 31.7 hours and 65.8 hours for the $600 \mu \mathrm{g}$ and $1200 \mu \mathrm{g}$ doses, respectively. Since the partial AUC in the $\gamma$ phase at the higher dose levels $(600 \mu \mathrm{g}$ and $1200 \mu \mathrm{g})$ contributed $<15 \%$ of the total AUC $_{\infty}$, the $t_{1 / 2, \beta}$ could be considered as the effective elimination $\mathrm{t}_{1 / 2}$.

The peak concentration $\mathrm{C}_{\max }$ was achieved rapidly, with $\mathrm{t}_{\max }$ occurring at approximately $0.25-0.5$ hours post-dose. PK exposures $\left(\mathrm{C}_{\max }, \mathrm{AUC}_{\text {last }}\right.$, and $\left.\mathrm{AUC}_{\infty}\right)$ were increased as the dose increased. The mean value of $\mathrm{CL} / \mathrm{F}$ was $8-13 \mathrm{~L} /$ hour across the tested doses from $100 \mu \mathrm{g}$ to $1200 \mu \mathrm{g}$. Depending on which phase was the detectable terminal phase, the mean values of $\mathrm{V}_{\mathrm{z}} / \mathrm{F}$ varied across doses: $40 \mathrm{~L}$ for the low doses $(10 \mu \mathrm{g}) ; 100-180 \mathrm{~L}$ for the intermediate doses $(30-300 \mu \mathrm{g})$; and 450-1200 L for the higher doses (600-1200 $\mu \mathrm{g})$.
The dose proportionality assessments based on statistical analyses were performed for PK exposures ( $\mathrm{AUC}{ }_{\infty}, \mathrm{AUC}_{\text {last}}$, and $\mathrm{C}_{\max }$ ), Table 4. Across the dose range from $2.5 \mu \mathrm{g}$ to $1200 \mu \mathrm{g}$, all three PK exposure parameters exhibited good proportionality with the regression slope values in the $\log$ (exposure)-dose model being close to one, although statistically the $90 \%$ confidence limits for the slopes fell slightly outside the pre-defined acceptance boundary $(0.964,1.036)$. Considering the variability and small sample size per dose group, the slight statistical deviations from proportionality were not considered clinically significant. Therefore, the PK exposures $\left(\mathrm{AUC}_{\infty}, \mathrm{AUC}_{\text {last }}\right.$, and $\mathrm{C}_{\max }$ ) of pasireotide could be considered to be approximately dose proportional.

\section{Pharmacodynamics}

On Day 1 in the placebo group, the mean $\mathrm{GH} \mathrm{AUC}_{2 \mathrm{~h}}$ was $22.7 \mathrm{ng} \cdot \mathrm{h} / \mathrm{mL}$. No reduction in $\mathrm{GH} \mathrm{AUC}_{2 \mathrm{~h}}$ was observed with pasireotide doses between $1 \mu \mathrm{g}$ and $10 \mu \mathrm{g}$. The $\mathrm{GH} \mathrm{AUC}_{2 \mathrm{~h}}$ decreased by approximately $45 \%$ in subjects administered pasireotide $30-100 \mu \mathrm{g}$. At pasireotide doses of $200 \mu \mathrm{g}$ and higher, the $\mathrm{GH} \mathrm{AUC}_{2 \mathrm{~h}}$ values decreased substantially to between $4.6 \mathrm{ng} \cdot \mathrm{h} / \mathrm{mL}$ and $1.0 \mathrm{ng} \cdot \mathrm{h} / \mathrm{mL}$. As shown in Table 5, suppression of $\mathrm{GH} \mathrm{AUC}_{2 \mathrm{~h}}$ was seen with pasireotide $200,300,600$, and $1200 \mu \mathrm{g}$.

The dose-response (defined as GH AUC reduction) and exposure-response relationships of pasireotide were well fitted by a direct inhibitory effect sigmoid $\mathrm{E}_{\max }$ model (Table 6). The pasireotide dose to yield half the maximal GH reduction $\left(\mathrm{ED}_{50}\right)$ was estimated to be $70.7 \mu \mathrm{g}$ (approximate 95\% confidence interval $[\mathrm{CI}]: 51.4-97.3 \mu \mathrm{g}$ ). The average pasireotide concentration expected to yield half the maximal

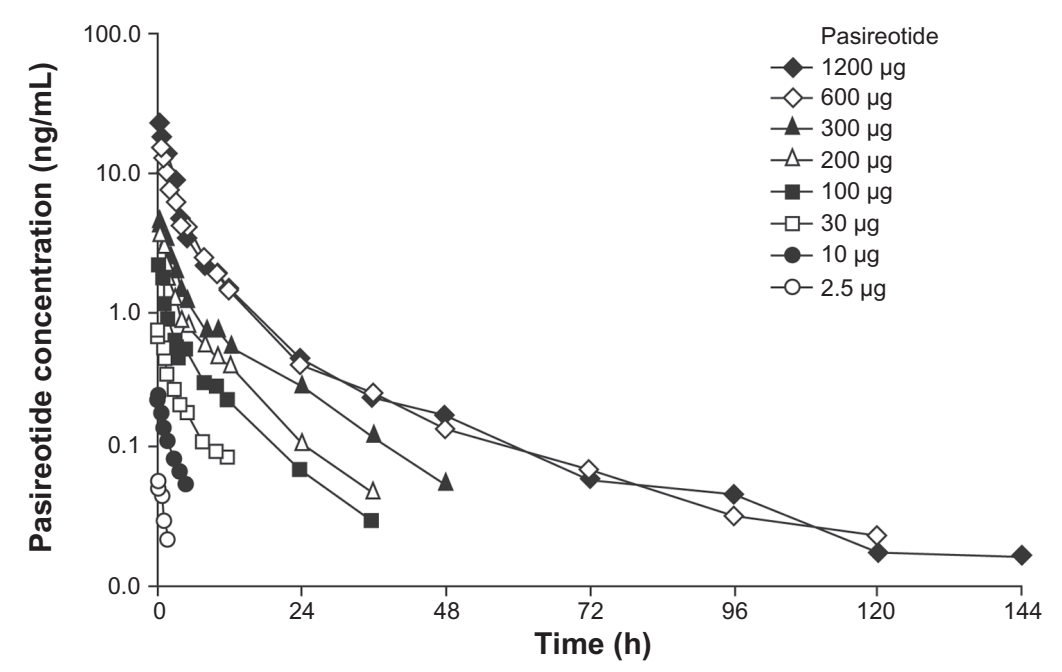

Figure 2 Pasireotide mean plasma concentration versus time profiles following a single subcutaneous dose of pasireotide in healthy volunteers. 
Table 3 Summary of pharmacokinetic parameters in healthy subjects administered a single subcutaneous dose of pasireotide $2.5-1200 \mu g$

\begin{tabular}{|c|c|c|c|c|c|c|c|c|c|c|}
\hline $\begin{array}{l}\text { Dose } \\
(\mu \mathrm{g})\end{array}$ & $\mathbf{n}$ & $\begin{array}{l}t_{\text {max }} \\
\text { (h) }\end{array}$ & $\begin{array}{l}C_{\max } \\
(\mathrm{ng} / \mathrm{mL})\end{array}$ & $\begin{array}{l}\text { AUC }_{\text {last }} \\
(\mathrm{ng} \cdot \mathrm{h} / \mathrm{mL})\end{array}$ & $\begin{array}{l}\text { AUC }_{\infty} \\
(\mathrm{ng} \cdot \mathrm{h} / \mathrm{mL})\end{array}$ & $\begin{array}{l}\text { CL/F } \\
\text { (L/h) }\end{array}$ & $\begin{array}{l}\mathbf{t}_{1 / 2, \alpha} \\
\text { (h) }\end{array}$ & $\begin{array}{l}\mathbf{t}_{1 /, \beta} \\
\text { (h) }\end{array}$ & $\begin{array}{l}\mathbf{t}_{1 / 2, \gamma} \\
\text { (h) }\end{array}$ & $\begin{array}{l}V_{z} / F \\
(L)\end{array}$ \\
\hline 2.5 & 6 & $0.25(0.25-0.50)$ & $0.06 \pm 0.01$ & $0.11 \pm 0.09$ & NA* & NA* & $2.6 \pm 1.4$ & NA* & NA* & NA* \\
\hline 10 & 6 & $0.25(0.25-0.25)$ & $0.24 \pm 0.06$ & $0.66 \pm 0.25$ & $N A^{*}$ & NA* & $2.0 \pm 0.5$ & NA* & NA* & $38.1 \pm 0.0$ \\
\hline 30 & 6 & $0.25(0.25-0.50)$ & $0.72 \pm 0.17$ & $2.78 \pm 1.02$ & $N A^{*}$ & NA* & $2.2 \pm 0.8$ & $7.4 \pm 2.2$ & NA* & $105.0 \pm 5.7$ \\
\hline 100 & 8 & $0.50(0.25-0.50)$ & $2.23 \pm 0.45$ & $9.10 \pm 2.37$ & $9.59 \pm 2.44$ & $11.00 \pm 2.67$ & $1.6 \pm 0.3$ & $8.1 \pm 1.4$ & $N A^{*}$ & $|3| .0 \pm 41.0$ \\
\hline 200 & 4 & $0.38(0.25-1.00)$ & $3.73 \pm 0.90$ & $16.8 \pm 3.65$ & $17.5 \pm 3.82$ & $11.90 \pm 2.56$ & $1.7 \pm 0.6$ & $7.8 \pm 2.1$ & NA* & $161.5 \pm 33.9$ \\
\hline 300 & 6 & $0.38(0.25-1.50)$ & $4.71 \pm 1.79$ & $26.0 \pm 6.87$ & $27.1 \pm 6.98$ & $11.9 \pm 3.88$ & $2.4 \pm 0.7$ & $10.7 \pm 1.0$ & $N A^{*}$ & $180.5 \pm 44.3$ \\
\hline 600 & 6 & $0.50(0.25-1.00)$ & $15.6 \pm 3.25$ & $75.6 \pm 11.2$ & $78.6 \pm 12.3$ & $7.82 \pm 1.39$ & $2.2 \pm 0.6$ & $9.1 \pm 5.2$ & $31.7 \pm 6.5$ & $464.0 \pm 439.6$ \\
\hline 1200 & 6 & $0.50(0.50-1.00)$ & $22.2 \pm 5.53$ & $90.4 \pm 13.2$ & $93.6 \pm 13.6$ & $13.1 \pm 2.09$ & $1.7 \pm 0.4$ & $9.1 \pm 2.1$ & $65.8 \pm 69.5$ & $1190.0 \pm 1572.3$ \\
\hline
\end{tabular}

Notes: *Not applicable due to limited data points in the terminal phase or the number of subjects with available parameters was less than $50 \%$ of the total enrolled subjects in this cohort. Data are median (range) for $\mathrm{t}_{\text {max }}$ and mean \pm standard deviation for all others. At the lowest dose of I $\mu \mathrm{g}$, pasireotide concentrations were below the LLOQ $(0.03 \mathrm{ng} / \mathrm{mL})$. For the doses between 2.5 and $30 \mu \mathrm{g}$, only a partial concentration versus time profile was detected (around 2-5 hours post-dose).

Abbreviations: AUC, area under the concentration-time curve; CL/F, apparent total body clearance; LLOQ, lower limit of quantification.

GH reduction $\left(\mathrm{EC}_{50}\right)$ was $0.3 \mathrm{ng} / \mathrm{mL}$ (approximate $95 \%$ CI: $0.2-0.7 \mathrm{ng} / \mathrm{mL}$ ).

\section{Discussion}

Following subcutaneous injection, pasireotide was well tolerated in healthy volunteers at doses up to $1200 \mu \mathrm{g}$. Among subjects receiving a dose of pasireotide $\leq 600 \mu \mathrm{g}$, two experienced an AE, neither of which was considered related to pasireotide. All six subjects who were administered pasireotide $1200 \mu \mathrm{g}$ experienced drug-related AEs, with nausea being the most frequently reported. These events were mild to moderate in severity and did not require intervention. No SAEs were observed in any dose group.

No subjects had clinically significant changes in laboratory parameters, vital signs, and ECG findings between administration of pasireotide and the end-of-study evaluation. Single doses of pasireotide 200-1200 $\mu \mathrm{g}$ were associated with glucose elevations in the first 2-6 hours post-dose compared with placebo, but this effect was transient and resolved within 23 hours post-dose, at which time glucose levels were normal for all groups. This profile is similar to the well-established safety profiles of currently available somatostatin analogs. ${ }^{13-17}$ Similar elevations in blood glucose levels have been

Table 4 Summary of linear regression values between logparameters and log-dose (doses of pasireotide 2.5-1200 $\mu \mathrm{g}$ )

\begin{tabular}{llll}
\hline PK parameters & Slope & \multicolumn{2}{l}{ Confidence interval } \\
\cline { 3 - 4 } & & Lower $\mathbf{9 0 \%}$ & Upper $\mathbf{9 0 \%}$ \\
\hline $\mathrm{AUC}_{\infty}(\mathrm{ng} \cdot \mathrm{h} / \mathrm{mL})$ & 1.01 & 0.93 & 1.08 \\
$\mathrm{AUC}_{\text {last }}(\mathrm{ng} \cdot \mathrm{h} / \mathrm{mL})$ & 1.14 & 1.09 & 1.19 \\
$\mathrm{C}_{\max }(\mathrm{ng} \cdot \mathrm{h} / \mathrm{mL})$ & 0.96 & 0.93 & 1.00 \\
\hline
\end{tabular}

Abbreviations: $A \cup C$, area under the concentration-time curve; $C_{\text {m, }}$, maximum observed plasma concentration after drug administration. observed in clinical trials of subcutaneous pasireotide (200-900 $\mu \mathrm{g}$ bid) in patients with Cushing's disease ${ }^{12,18}$ and acromegaly.

The PK profile of pasireotide was characterized by fast absorption, low clearance, long half-life, and extensive distribution in healthy volunteers. Compared with octreotide, which has a mean $\mathrm{t}_{1 / 2}$ of approximately 1.7 hours, ${ }^{19}$ pasireotide has a much longer half-life, which is not surprising considering that its chemical structure is more metabolically stable than that of octreotide. Pasireotide concentrations showed multi-exponential declines following a subcutaneous injection, and the $\gamma$ phase was not always observed at low dose levels. Since the $\gamma$ phase only contributes a small portion of the total AUC, it is appropriate to consider that the effective elimination $t_{1 / 2}$ is similar to the $t_{1 / 2, \beta}$ of approximately 7-11 hours. Based on this effective elimination $t_{1 / 2}$, subcutaneous pasireotide is suitable for a twice-daily (bid) dosing regimen, which is less frequent than subcutaneous octreotide (3-4 times/day dosing) and can thus provide greater conve-

Table 5 Percentage change in median $\mathrm{GH} \mathrm{AUC}_{2 h}$ by dose group following a single subcutaneous dose of pasireotide or placebo

\begin{tabular}{llll}
\hline $\begin{array}{l}\text { Dose } \\
(\mu \mathrm{g})\end{array}$ & $\mathbf{n}$ & $\begin{array}{l}\text { Change in median } \\
\mathrm{GH} \mathrm{AUC}_{2 \mathrm{~h}}, \%\end{array}$ & $\begin{array}{l}\text { Range of change in median } \\
\mathbf{G H ~ A U C}_{2 \mathrm{~h}}, \% \text { min, max }\end{array}$ \\
\hline 0 & 18 & -11.9 & $-74.4,170.0$ \\
1 & 6 & 8.1 & $-76.3,33.6$ \\
2.5 & 6 & 23.8 & $-41.5,125.8$ \\
10 & 6 & 1.0 & $-26.1,70.4$ \\
30 & 6 & -45.3 & $-66.5,24.7$ \\
100 & 8 & -46.2 & $-72.8,575.9$ \\
200 & 4 & -79.1 & $-85.3,-67.9$ \\
300 & 6 & -86.7 & $-93.6,-64.9$ \\
600 & 6 & -82.5 & $-96.5,-59.6$ \\
1200 & 6 & -95.7 & $-97.1,-87.9$ \\
\hline
\end{tabular}

Abbreviations: AUC, area under the concentration-time curve; $\mathrm{GH}$, growth hormone. 
Table 6 Dose-response and exposure-response relationship between pasireotide level (by dose and $\mathrm{C}_{\text {avg }}$ ) and $\mathrm{GH}$ suppression

\begin{tabular}{|c|c|c|c|}
\hline \multirow[t]{2}{*}{ PK parameters } & \multirow{2}{*}{$\begin{array}{l}\text { Value } \pm \text { standard } \\
\text { error }\end{array}$} & \multicolumn{2}{|c|}{ Confidence interval } \\
\hline & & Lower $90 \%$ & Upper $90 \%$ \\
\hline \multicolumn{4}{|c|}{ Non-linear $\mathrm{E}_{\max }$ model for GH AUC ratio versus dose } \\
\hline $\mathrm{ED}_{50}(\mu \mathrm{g})$ & $70.72 \pm 0.16$ & 51.40 & 97.30 \\
\hline $\mathrm{E}_{\max }$ & $1.00 \pm 0.00$ & 1.00 & 1.00 \\
\hline \multicolumn{4}{|c|}{ Non-linear $E_{\max }$ model for $\mathrm{GH}$ AUC ratio versus $C_{\text {avg }}$} \\
\hline $\mathrm{EC}_{50}(\mathrm{ng} / \mathrm{mL})$ & $0.33 \pm 0.34$ & 0.17 & 0.65 \\
\hline $\mathrm{E}_{\max }$ & $0.99 \pm 0.03$ & 0.93 & 1.05 \\
\hline
\end{tabular}

Abbreviations: $A \cup C$, area under the concentration-time curve; $C_{\text {avg }}$, average pasireotide plasma concentration; $\mathrm{EC}_{50}$, pasireotide concentration to yield half the maximum $\mathrm{GH}$ reduction; $\mathrm{ED}_{50}$, pasireotide dose to yield half the maximum $\mathrm{GH}$ reduction; $\mathrm{GH}$, growth hormone; $\mathrm{PK}$, pharmacokinetics.

nience and potentially lead to improved patient compliance during long-term treatment.

The exploratory GHRH stimulation test demonstrated that pasireotide has dose-dependent activity in suppressing GH secretion. The effect was not evident at the lower doses $(1,2.5$, and $10 \mu \mathrm{g})$, and only a small effect was observed for the $30 \mu \mathrm{g}$ and $100 \mu \mathrm{g}$ doses. The suppression of GH secretion was significant for the higher dose levels $(\geq 200 \mu \mathrm{g}$ ), suggesting that the exposure achieved at pasireotide doses $\geq 200 \mu \mathrm{g}$ may be therapeutic for GH suppression. A Phase II study in patients with acromegaly has confirmed these findings, ${ }^{7}$ and a large, randomized, Phase III trial using a longacting formulation of pasireotide (pasireotide long-acting release) is ongoing. ${ }^{9}$ It is possible that the administration of high doses of pasireotide could induce GH suppression in patients with normal GH levels prior to treatment (ie, patients with Cushing's disease), and further investigation in future studies may be of interest.

\section{Conclusion}

In summary, pasireotide demonstrated good safety, tolerability, and PK profiles in healthy volunteers. The enhanced binding profile of pasireotide, targeting $\mathrm{sst}_{1,2,3}$ and $\mathrm{sst}_{5}$, makes this agent a potential therapy for patients with acromegaly and NET who are untreated or refractory/resistant to octreotide or lanreotide, as well as for patients with Cushing's disease. Ongoing Phase II and III studies are in progress to confirm the efficacy and safety of this agent in these patient populations.

\section{Acknowledgments}

Financial support for medical editorial assistance was provided by Novartis Pharmaceuticals Corporation, Basel, Switzerland. We thank Helene Darmofal, Mudskipper Bioscience, for medical editorial assistance with this manuscript.

\section{Disclosure}

This study was funded by Novartis Pharma AG. GG has no conflicts of interest to declare. $\mathrm{KH}, \mathrm{MR}, \mathrm{AB}, \mathrm{EB}, \mathrm{YW}$, and $\mathrm{MM}$ are employees of Novartis.

\section{References}

1. Bruns C, Lewis I, Briner U, Meno-Tetang G, Weckbecker G. SOM230: a novel somatostatin peptidomimetic with broad somatotropin release inhibiting factor (SRIF) receptor binding and a unique antisecretory profile. Eur J Endocrinol. 2002;146(5):707-716.

2. Schmid HA. Pasireotide (SOM230): development, mechanism of action and potential applications. Mol Cell Endocrinol. 2008;286(1-2):69-74.

3. Susini C, Buscail L. Rationale for the use of somatostatin analogs as antitumor agents. Ann Oncol. 2006;17(12):1733-1742.

4. Lewis I, Bauer W, Albert R, et al. A novel somatostatin mimic with broad somatotropin release inhibitory factor receptor binding and superior therapeutic potential. J Med Chem. 2003;46(12):2334-2344.

5. Schmid HA. Preclinical evidences suggest new treatment options for endocrine disorders: Pasireotide (SOM230) and Everolimus (RAD001). Ann Endocrinol (Paris). 2008;69(2):162-163.

6. van Der Hoek J, de Herder WW, Feelders RA, et al. A single-dose comparison of the acute effects between the new somatostatin analog SOM230 and octreotide in acromegalic patients. J Clin Endocrinol Metab. 2004;89(2):638-645.

7. Petersenn S, Schopohl J, Pasireotide Acromegaly Study Group, et al. Pasireotide (SOM230) demonstrates efficacy and safety in patients with acromegaly: a randomized, multicenter, Phase II trial. J Clin Endocrinol Metab. 2010;95(6):2781-2789.

8. Colao A, Fleck J, Pain S, et al. Pasireotide LAR versus octreotide LAR or lanreotide autogel in patients with inadequately controlled acromegaly: A Phase III, multicenter, randomized, parallel-group study. ENEA Abstracts. 2010;82-83:Abst OC-6.2.

9. Bronstein M, Gu F, Shen C-C, et al. A randomized, blinded, multicenter, Phase III study to assess the efficacy and safety of pasireotide LAR versus octreotide LAR in patients with active acromegaly. ENEA Abstracts. 2010;82:Abst OC-6.1.

10. Kvols L, Glusman JE, Pasireotide Carcinoid Study Group, et al. The effects of pasireotide (SOM230) on health-related quality of life in patients with metastatic carcinoid tumors refractory or resistant to octreotide LAR. J Clin Oncol. 2007;25(18S)(Suppl.):Abst 4558. Available from: http://meeting.ascopubs.org/cgi/content/ abstract/25/18_suppl/4558. Accessed February 22, 2012.

11. Kvols L, Oberg K, Pasireotide Carcinoid Study Group, et al. Efficacy, safety and pharmacokinetic results from a Phase II study of pasireotide (SOM230) in the treatment of patients with metastatic NETs refractory or resistant to octreotide LAR. Neuroendocrinology. 2010;92(1):Abst C57.

12. Colao A, Petersenn S, Newell-Price J, et al. A 12-month Phase 3 study of pasireotide in Cushing's disease. $N$ Engl J Med. 2012; 366(10):914-924.

13. Cook D. Octreotide long-acting repeatable in acromegaly: achieving optimal control. The Endocrinologist. 2009;19(3):142-147.

14. Croxtall JD, Scott LJ. Lanreotide Autogel: a review of its use in the management of acromegaly. Drugs. 2008;68(5):711-723.

15. Oberg K. Somatostatin analog octreotide LAR in gastro-enteropancreatic tumors. Expert Rev Anticancer Ther. 2009;9(5): 557-566.

16. Ipsen Ltd. Somatuline ${ }^{\circledR}$ depot (lanreotide) injection prescribing information. March 2011. Available from: http:/www.somatulinedepot. com/hcp/pdf/SomatulineDepot_Full_Prescribing_Information.pdf. Accessed February 22, 2012.

17. Novartis Pharmaceuticals Corporation. Sandostatin ${ }^{\circledR}$ LAR Depot (octreotide acetate for injectable suspension) prescribing information. September 2011. Available from: http://www.pharma.us.novartis. com/product/pi/pdf/sandostatin_lar.pdf. Accessed February 22, 2012 . 
18. Boscaro M, Ludlam WH, Atkinson B, et al. Treatment of pituitary dependent Cushing's disease with the multi-receptor ligand somatostatin analog pasireotide (SOM230): a multicenter, phase II trial. J Clin Endocrinol Metab. 2009;94(1):115-122.
19. Ma P, Wang Y, Van Der Hoek J, et al. Pharmacokinetic-pharmacodynamic comparison of a novel multiligand somatostatin analog, SOM230, with octreotide in patients with acromegaly. Clin Pharmacol Ther. 2005;78(1):69-80.

\section{Publish your work in this journal}

Drug Design, Development and Therapy is an international, peerreviewed open-access journal that spans the spectrum of drug design and development through to clinical applications. Clinical outcomes, patient safety, and programs for the development and effective, safe, and sustained use of medicines are a feature of the journal, which has also been accepted for indexing on PubMed Central. The manuscript management system is completely online and includes a very quick and fair peer-review system, which is all easy to use. Visit http://www.dovepress.com/testimonials.php to read real quotes from published authors.

Submit your manuscript here: http://www.dovepress.com/drug-design-development-and-therapy-journal 